\title{
"Fear and loathing across party lines" (also) in Europe: Affective polarisation in European party systems ${ }^{1}$
}

\author{
Andres Reiljan ${ }^{2}$ \\ European University Institute, Florence, Italy
}

\begin{abstract}
Several US scholars have recently addressed an increased partisan animosity between Democrats and Republicans, and have termed this phenomenon "affective polarisation". This surge in partisan affective polarisation is perceived to be highly problematic, as it has been found to have a negative impact on the functioning of the party system and even society at large. The aim of this paper is to study the concept of affective polarisation in European party systems. The paper introduces the Affective Polarisation Index that allows for measuring and comparing levels of affective polarisation also in multiparty systems. This novel measure is applied to 22 European democracies and the United States between 2005 and 2016. The results indicate that affective polarisation is acutely present in European party systems, as partisans are often extremely hostile towards competing parties. The most affectively polarised countries are in Central Eastern and Southern Europe where the degree of affective polarisation is notably higher than it is in the United States, while Northwestern European countries are more moderate in terms of partisan feelings. Further analysis reveals that affective polarisation is significantly correlated with ideological polarisation, but the relationship between the two appears to be conditional: in some Western European political systems ideological polarisation does not lead to strong interparty hostility, while in Central Eastern Europe, a high degree of affective polarisation can be present even in ideologically centrist party structures. These findings validate the claim that ideological and affective polarisation are two distinct aspects of polarisation, and that the latter, too, merits additional attention.
\end{abstract}

Keywords: Polarisation; Affective polarisation; Political parties; Attitudes

\footnotetext{
${ }^{1}$ This is the accepted version of the following article: Reiljan, A. (2020). 'Fear and loathing across party lines'(also) in Europe: Affective polarisation in European party systems. European Journal of Political Research, 59(2), 376396, which has been published in final form at: https://doi.org/10.1111/1475-6765.12351

2 E-mail: andres.reiljan@gmail.com
} 


\section{Introduction}

In most of the academic literature, political polarisation has been almost exclusively equated with ideological polarisation (henceforth IP). Recently, the dominance of the IP paradigm has been challenged by a number of mostly US-based scholars who have started to define polarisation in terms of partisan affect. The term "affective polarisation" (henceforth AP) had been sparsely used in some previous research (e.g. Richardson 1991; Hetherington \& Weiler 2009), but did not have much impact until the seminal article of Iyengar et al. (2012). AP, according to their definition, is a tendency among party supporters (partisans) to view other party/parties as a disliked out-group(s), while holding positive in-group feelings for one's own party. They found that AP has dramatically surged among the US partisans during the last decades on the account of increased hostility between Republicans and Democrats. This study catapulted the affective approach to the forefront of the polarisation debate in the USA, and a number of notable contributions have followed (see Hetherington \& Rudolph 2015; Iyengar \& Westwood 2015; Mason 2015, 2016; Rogowski \& Sutherland 2016; Lelkes et al. 2017; Webster \& Abramovitz 2017; Levendusky 2018; Iyengar \& Krupenkin 2018).

From the normative perspective, political polarisation is usually considered as a problematic phenomenon. However, a certain degree of IP is necessary to make party competition function properly, as it indicates that voters have a meaningful choice between alternating policy packages (Barber \& McCarty 2015). AP, however, is unequivocally considered as a negative and dangerous phenomenon, as it decreases political trust among the supporters of the party that lost the election, hinders cooperation among party elites (Hetherington \& Rudolph 2015) and even induces discriminatory behaviour toward opposing partisans outside the political sphere (Iyengar \& Westwood 2015). Thus, we should desire a party system where parties and partisans diverge on ideological grounds to some extent, but this is not accompanied by intense inter-party animosity.

Despite the gravity of the topic in the United States, the debate on AP in Europe is nearly nonexistent. Few authors have considered the concept in certain European countries (see Richardson 1991; Hansen \& Kosiara-Pedersen 2017; Westwood et al. 2018), but to the best of my knowledge, no broad cross-national comparative study concentrating on AP in Europe has been conducted yet. Thus, we do not know how European countries fare in terms of AP compared to each other and to the USA, not to mention the possible causes and consequences of it. Regarding the foundations of AP and IP-AP linkage, the current results from the US 
literature are ambiguous, as some scholars claim that IP has a strong effect on AP (Rogowski \& Sutherland 2016; Webster \& Abramovitz 2017), while others downplay the importance of this relationship (Iyengar et al. 2012). Adding a vast number of European countries into this debate could help reveal many possible IP-AP combinations on party system level and bring more clarity into the question of what facilitates negative feelings among partisans towards the political opponents.

In a public lecture given in 2011, Shanto Iyengar described the mutual feelings between the Democrats and the Republicans as "fear and loathing across party lines" (see also Iyengar \& Westwood 2015). He also emphasised the necessity to conduct comparative studies to find out whether the United States is the most affectively polarised country, and discussed a possibility that some "tribal societies" could exhibit more extreme inter-group hostility. In this article, I demonstrate that the level of AP in the United States is actually exceeded by a number of democratic European countries. To enable such cross-national comparison, I will introduce an index to measure and compare AP also in multiparty systems. I measure AP in more than twenty European party systems and examine the IP-AP relationship cross-nationally. I show that although the two manifestations of polarisation are correlated to each other, they are far from congruent and should be treated as separate concepts.

\section{The Concept of Affective Polarisation in the Wider Framework of Polarisation Studies}

In a broad sense, polarisation is defined as a clustering within the society that divides the population into sizeable groups on opposite sides. The degree of polarisation is determined by the distance between, the homogeneity within and the size of these opposing groups (Esteban \& Ray 1994: 824). Probably the most commonly used "anchor" of group identity in polarisation studies has been the political party. Accordingly, the degree of polarisation is determined by the distance between, the coherence within and the size of the parties. As already noted, between-group distance and in-group homogeneity have usually been defined in ideological terms: how far are the parties from each other in the ideological space and how ideologically coherent are they within.

The AP approach also defines polarisation by the distance between and coherence within parties. However, in the AP framework, these attributes derive from direct attitudes towards the parties. One side of the equation is the in-party evaluation: how favorable is the partisan towards 
her own party. The second element is out-party evaluation(s): how negative is the partisan towards the competing party/parties. Thus, instead of ideological dimensions, we have to consider the affective ones, with the extremes of the continuum being a very negative and a very positive feeling towards the party. The centerpoint of the dimension represents an indifferent or neutral perception. AP is present when the attitudes towards the in- and out-parties are on different sides of the neutral point, and the closer the evaluations are to the extremes of the affective spectrum, the higher is the degree of AP.

Figure 1 illustrates this compatibility between the two types of polarisation in a hypothetical party system with two parties and two ideological dimensions. Left panel of Figure 1 depicts the ideological distance between economically right-conservative Party A and left-liberal Party B. Right side of Figure 1 illustrates the affective distance between the parties, defined by the like-dislike evaluations of the party supporters. The $\mathrm{x}$-axis is based on the attitudes towards Party A, ranging from very negative to very positive, while the feelings towards Party B are on the y-axis. In line with the ideological placement of the two parties, the supporters of Party A are highly positive about their own party, while showing negative affect for Party B, and vice versa. Thus, Figure 1 demonstrates that AP can be presented as a spatial phenomenon, similarly to IP.
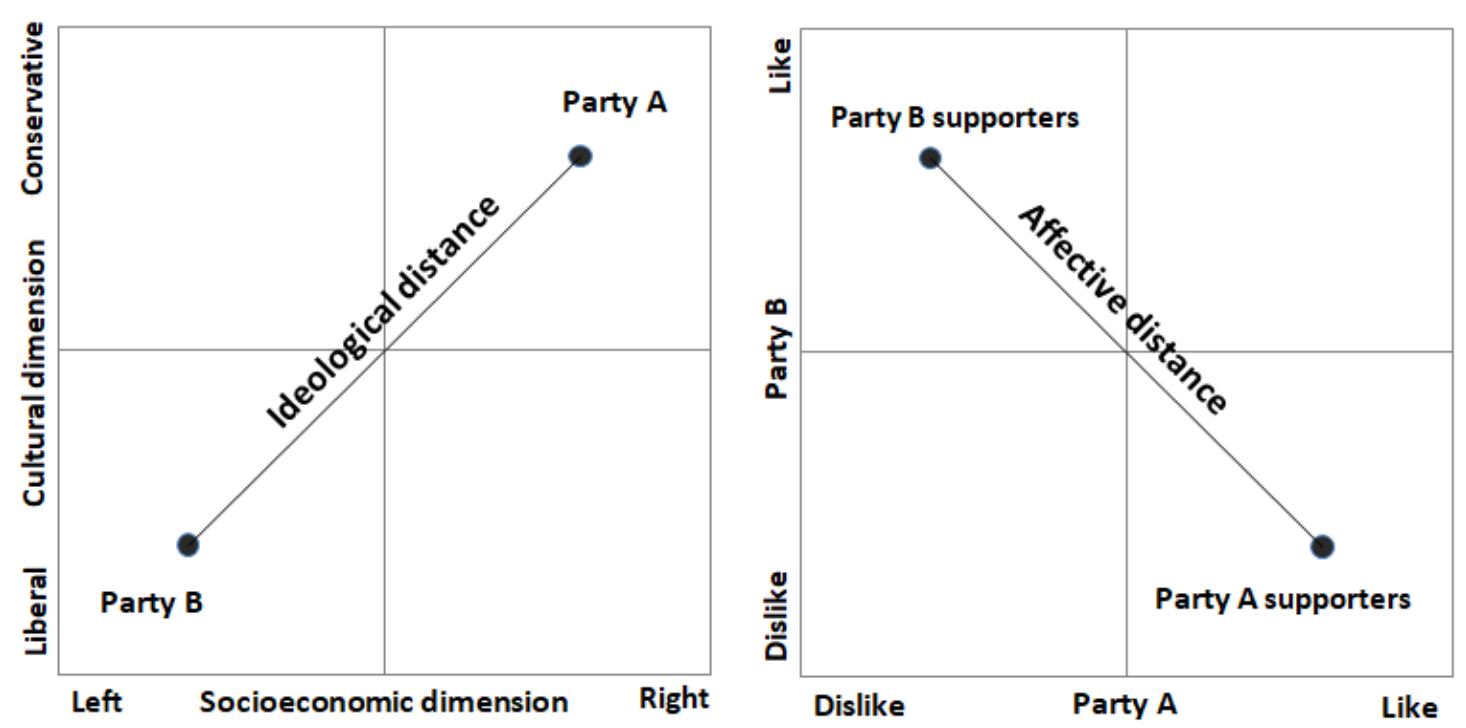

Figure 1. Spatial representation of ideological and affective distance.

On Figure 1, the affective distance between the parties is defined by party supporters' attitudes. This relates to a frequently used distinction between the supply and the demand side of party 
systems and polarisation. Supply-side polarisation refers to distances between the political parties on the elite level, while demand-side polarisation reflects the divergence among the electorate (Kriesi et al. 2006; Pardos-Prado \& Dinas 2010). If the concept of IP has often been applied to both sides of the electoral competition, then AP has in the current literature always been considered as a demand-side phenomenon, i.e. it has been measured via the attitudes of party supporters. Conceptually, AP is applicable also to the supply side of the party competition; however, there is very little data available which allows an empirical study of the concept at the elite level. Accordingly, in the following theoretical and empirical sections, AP will be treated as a demand-side phenomenon.

The concept of political polarisation is often discussed with regard to its normative implications. Although the negative consequences of AP - such as legislative gridlock - are most visible on the elite level, demand-side AP can also have highly adverse effects on public policy outcomes and even people's daily lives. Hetherington and Rudolph (2015) demonstrate that the more negative feelings partisans have towards the out-party, the more reluctant they are to support any policies initiated by the government led by that party. Politicians in the USA have been fairly responsive to their constituents: if consensus develops among Democrat and Republican voters, legislative productivity increases; conversely, if dissensus and negative partisanship prevail among the electorate, the opposition party elites will do everything to block the initiatives of the government, leading to gridlock (Hetherington and Rudolph 2015: 3-4, 142143). This affective responsiveness also manifests itself in harsh rhetoric between party elites, reinforcing the negative spiral even more (Iyengar and Krupenkin 2018: 215). Thus, an affectively polarised mass public can become a force that boosts conflict on the elite level, even if the initial polarising messages originated from the elite itself (Hetherington and Rudolph 2015: 6). Moreover, the negative consequences of AP are not limited to the political sphere and can directly affect people's daily lives by inducing discrimination in other sectors of society, such as the job market. In the US society, partisan prejudice is now so strong that it even exceeds discrimination based on race, prompting some scholars to term this phenomenon as "partyism" (Iyengar and Westwood 2015; Sunstein 2015).

Although current literature has considered the consequences of AP only in a presidential twoparty system, I believe it could also help to better understand the role of polarisation in a parliamentary multiparty context. In fragmented systems, parties usually need to form coalitions in order to assemble governments, which can prove very difficult if hostility and distrust exists between parties/partisans (Warwick 1994: 3). Studies of coalition patterns in 
multiparty systems have shown that sheer ideological distance - although being an important determinant - cannot fully explain the (un)willingness of political parties to co-operate with each other (Budge and Laver 1992). In some cases, parties are prepared to form coalitions across cleavages, while rejecting co-operation with ideological "neighbours"; a vivid example is Ireland, where the two main centre-right parties have never agreed to govern together due to deep partisan hostility that dates back to the Irish Civil War in 1920s (Laver 1992). In many contemporary European party systems, the right-populist parties invoke the highest degree of negative emotions among the public (Mudde and Rovira Kaltwasser 2018: 1685), whereas on the ideological dimensions, people often do not place these parties to the most extreme positions (De Angelis 2017). As we have witnessed in several countries, even the mainstream rightconservative parties are reluctant to form coalitions with the right-populists, which in some cases has led to arduous government formation processes and grand coalitions across the leftright division. It appears that in multiparty systems, party elites respond to high AP among their constituents with an unwillingness to form coalitions with loathed out-parties. Thus, high AP in a multiparty system can make it very difficult to form functional governments.

Based on the preceding discussion, I find that the concept of AP fits well into the wider framework of political polarisation. AP can be presented in spatial terms, it is compatible with the supply-demand distinction and is likely to be relevant in both two- and multiparty systems. The central difference between the affect-based approach and the ideological paradigm is that IP derives from diverging positions taken by the parties and party supporters with regard to ideological issues and dimensions, whereas AP is determined by direct attitudes towards specific parties. Thus, a high level of IP does not necessarily signify animosity between the polarised parties, but it can form the basis for it (Persily 2015: 6-7). AP, on the other hand, indicates the interparty hostility directly, without saying anything about its basis (Lelkes 2016: 401). IP and AP could, therefore, be considered as complementary to each other, and the exact relationship between the two should be determined empirically.

\section{Measuring Affective Polarisation in Multiparty Systems}

To fulfil the first aim of this article - comparing the levels of AP cross-nationally - I need a measure that can appropriately estimate party system level AP also in multiparty context. To the best of my knowledge, no AP index exists yet - probably because the literature has hitherto focused on the US party system, where measuring AP is methodologically quite simple. The 
American National Election Studies (ANES) survey includes a question where respondents are asked to evaluate the political parties on a thermometer scale from 0 to 100 degrees where $0^{\circ}$ means the most negative attitude towards the party, $50^{\circ}$ signifies a neutral stance and $100^{\circ}$ equals to the most positive rating. As the two groups are considered equal in their relative importance, the results are not weighted: AP is the average in-party/out-party evaluation difference among Republicans and Democrats (Iyengar et al. 2012; Webster and Abramowitz 2017).

However, in European multiparty systems, there are usually more than two relevant parties and due to greater variation in party vote shares, the relative importance of each party is more uneven compared to the USA. To obtain an accurate estimation of party system AP, it should not be overlooked that vast distances between sizable parties signify greater polarisation from the perspective of the whole system compared to when similar distances are present between smaller fringe parties (Dalton 2008: 906). Thus, to conduct a valid cross-national comparison of AP, it is necessary to: a) include the in-party and out-party evaluations of the supporters of all the relevant parties (and towards all the relevant parties); b) account for the size of the parties.

To fulfil these conditions, I have conducted the Affective Polarisation Index (API) that indicates the average divergence of partisan affective evaluations between in-party and out-parties, weighted by the electoral size (vote share) of the parties. ${ }^{3}$ To make the computing procedure easier to follow, I explain the calculation of API in two steps, before presenting the full equation.

In the first step I calculate the AP score for each partisan group (i.e. supporters of a party) by subtracting the average evaluations towards out-parties from the average in-party evaluation. The in-party/out-party subtractions will be weighted with the vote shares of the out-parties and then summed up. Therefore, in a party system with $N$ relevant parties, the relative AP of every party is:

$\mathrm{AP}_{n}=\sum_{\substack{m=1 \\ m \neq n}}^{N}\left[\left(\right.\right.$ Like $_{n}-$ Like $\left.\left._{m}\right) \times\left(\frac{\text { Vote }_{\text {share }}}{1-\text { Vote }_{\text {share }}}\right)\right]$

"Like" signifies the attitude towards the party, corresponding to the previously described thermometer ratings. " $n$ " denotes the in-party and " $m$ " refers to the out-party. The " $1-$ vote

\footnotetext{
${ }^{3}$ I thank Simon Skipka for his advice on how to properly write down the index equation.
} 
share" is necessary to exclude the in-party vote share from this part of the calculation, so the combined vote shares of the out-parties would equal to $100 \%$.

In the second step, I weight these party AP scores with the vote shares of the respective party $($ Partyn $)$ and sum all the scores up to get the weighted average which is the Affective Polarisation Index:

$\operatorname{API}=\sum_{n=1}^{N}\left(\operatorname{AP}_{n} \times\right.$ Vote share $e_{n}$

The complete API formula is therefore:

API $=\sum_{\mathrm{n}=1}^{\mathrm{N}}\left[\sum_{\substack{\mathrm{m}=1 \\ \mathrm{~m} \neq \mathrm{n}}}^{\mathrm{N}}\left(\left(\right.\right.\right.$ Like $_{\mathrm{n}}-$ Like $\left.\left._{\mathrm{m}}\right) \times\left(\frac{\text { Vote }_{\text {share }}}{1-\text { Vote share }_{\mathrm{n}}}\right)\right) \times$ Vote share $\left._{\mathrm{n}}\right]$

It must be noted that API leaves out a substantial part of the electorate: non-partisans, i.e. the people who do not identify with any political party. However, I find this unavoidable, as affective attitudes can only be measured in relation to specific groups. It would be possible to extract the attitudes of non-partisans towards all the parties, but not vice versa. Therefore, I will proceed with the index that accounts for only the respondents who have partisan identity. To minimize the amount of people who are excluded from index calculations, I use a lenient way to define partisanship, also including the so-called "leaners" (Petrocik 2009). The data used to calculate API in this article and some other technical details will be explained in the data and variable operationalisation section.

\section{The Linkage Between Ideological and Affective Polarisation}

The second main aim of this article is to explore the relationship between ideological and affective polarisation among European countries. From the current US literature, two general conclusions about the IP-AP relationship can be drawn. First, AP and IP are not congruent, as AP is much more intense. Although the ideological distance between Democrats and Republicans has increased over the last decades, the majority of partisans are still ideologically centrist or just slightly leaning to either side of the liberal-conservative continuum (Lelkes 2016; Webster \& Abramowitz 2017). As for AP, on the other hand, more than half of the partisans evaluate the opposing party on the feelings thermometer with a rating of less than 30 
out of 100, while giving over 70 to one's own party (Hetherington \& Rudolph 2015: 16, 31). Clearly, the distance between the parties, as illustrated on the previously presented Figure 1, is greater on affective dimensions compared to ideological ones. Secondly, despite this incongruence, high IP does increase AP. The relative strength of this linkage varies - probably due to slight differences in the studied time periods, the way ideology is operationalised and exact model specifications -, but all the authors who have studied it, have found a statistically significant positive relationship between IP and AP (Iyengar, et al. 2012; Mason 2015; Rogowski \& Sutherland 2016; Webster \& Abramowitz 2017). These results confirm that partisans who hold more extreme policy positions are, on average, affectively more polarised. Also, if party candidates are perceived to be more distant from each other, it increases AP (Rogowski and Sutherland 2016).

Although these two observations about the IP-AP relationship in the USA are not mutually exclusive, some authors strongly emphasise one over the other, leading them to tie AP to different theoretical underpinnings. The scholars that highlight the incongruence between IP and AP perceive partisanship as a social identity and draw insights from social identity theory (Iyengar et al. 2012). This relates to the classic work of Campbell et al. (1960) who demonstrated that the American voter is ideologically rather unstructured and the connection with a party is more emotional than rational (Mason 2015). Accordingly, these authors downplay the IP-AP relationship and describe AP as predominantly driven by the heightened sense of group competition among partisans, which is fuelled by increasingly negative and longlasting political campaigns (Iyengar et al. 2012), and developments in the media environment that have occurred in the era of broadband internet (Lelkes et al. 2017; Hetherington \& Rudolph 2015). The alternative approach emphasises the finding that IP is related to AP. Theoretically, this account builds on Downs (1957) who modelled voters as ideologically motivated rational actors. In the case of high IP, partisans perceive the stakes in political competition to be higher and respond by developing affectively polarised views on parties/candidates (Rogowski \& Sutherland 2016: 486). As such, AP among the US partisans can be considered to have a strong rational basis (Webster \& Abramowitz 2017: 643). However, just as the scholars relying on the social identity theory are not denying that IP has an effect on AP, Webster and Abramowitz (2017: 635) also concede that there is a "tribal" element in partisan feelings and AP cannot be perceived as a completely rational phenomenon.

Insights from the US literature, therefore, suggest that there is a partial connection between IP and AP. However, these studies are limited to just one country and focus on the individual level, 
whereas my aim is to map the IP-AP relationship cross-nationally. To generalise, we can expect four different combinations: high IP/high AP; low IP/low AP; high IP/low AP and low IP/high AP. Traditionally, European politics have been structured by deep underlying cleavages, making ideology important to both elites and partisans, while the US partisanship has been characterised by less ideological constraint (Richardson 1991: 753-754; Hetherington \& Rudolph 2015: 55). Although the importance of traditional cleavages has declined in European politics during the last decades (Kriesi et al. 2006), it is still reasonable to expect that many countries are placed in either the low IP/low AP or high IP/high AP quadrants, indicating that AP is significantly related to IP in Europe. Considering the previously described findings from the US literature, then in comparison with the European countries, I presume the USA to be located in the low IP/high AP category. It is possible that also some European countries deviate from the low IP/low AP-high IP/high AP diagonal. I find it likely that some ideologically less structured post-communist democracies could be placed in the same low IP/high AP category as (presumably) the USA. It is not surprising that strong negativity towards out-parties is evident in this region (Mudde and Rovira Kaltwasser 2018: 1684), but it is unknown whether this is accompanied by positive in-party attitudes, which is also a presumption of high AP. Conversely, in some countries, ideological distance might not coincide with a negative partisan affect. It should be especially probable in consociational democracies (see Lijphart 1969), where parties often form coalitions across ideological divisions. Such coalitions could curb the negative partisan affect, even if parties and partisans remain ideologically distant (Westwood et al. 2018). ${ }^{4}$ These countries could, then, reside in the high IP/low AP sector. Thus, I find it possible that all four IP-AP combinations are present in Europe.

Regarding IP, defining the relevant dimension(s) of conflict is slightly more complicated than it is for AP, especially in a cross-national context. Since Downs (1957), the most commonly used basis for cross-national comparisons has been the left-right continuum. As Mair (2007) demonstrates, it has broad acceptability among voters and parties in both Western European and post-communist Central Eastern European countries. This does not imply that the left-right division has an identical issue and cleavage basis across countries, but rather that it captures whatever are the main conflicts within the political system (Inglehart 1990; Dalton 2008). Thus, I will consider IP in the party system to be higher, the more parties are distant from each other on the left-right dimension, while acknowledging some limitations of this approach, which will

\footnotetext{
${ }^{4}$ As discussed in the conceptualisation section, forming such coalitions already presupposes a certain level of trust between partisans, so the direction of causation can work both ways.
} 
be discussed in the empirical section of this article. It is important to clarify that parties are defined both on the supply and demand sides. This means that in addition to parties being polarised on the elite level, party supporters are supposed to be aligned with their party ideologically, i.e. the supporters of left-wing parties place themselves on the left side of the spectrum, and right-wing party supporters to the right (regarding the importance of partisanideological alignment, see Mason 2015). This consideration will be revisited in the variable operationalisation section.

Based on the preceding discussion, my central assumption is that ideologically more polarised party systems have, on average, higher partisan AP. However, I do not expect the correlation to be perfect and find it likely that a number of cases will diverge by either exhibiting high AP even in ideologically non-polarised settings or moderate partisan feelings despite high IP. Although this study is exploratory and does not test specific hypotheses, I hope that the results presented in the next sections will help to advance both empirical and theoretical understandings of the determinants of AP.

\section{Data and Variable Operationalisation}

My empirical analysis relies on data from the Comparative Study of Electoral Systems (CSES). ${ }^{5}$ I have included all European countries that are considered to be electoral democracies ${ }^{6}$ and for which data is available. Unfortunately, the data coverage of CSES is rather sporadic. Many European democracies are not part of the project, and some countries have participated in the survey only once, whereas for others there is data for several elections. Moreover, there were differences in the way partisan identity questions were administered in the first two waves of CSES compared to the third and fourth module. Therefore, to ensure that my comparisons are valid, I only use data from the third and fourth wave. The final sample includes 22 European countries (and the United States) and 38 elections, covering a time period from 2005 to 2016 . I only included parliamentary election data, as I use party vote shares to calculate AP and IP measures. Thus, presidential elections are not suitable, as the votes are attributed to candidates, not directly to parties.

\footnotetext{
${ }^{5}$ Data can be downloaded from www.cses.org

${ }^{6}$ Based on the Freedom in the World report by Freedom House (https://freedomhouse.org/)
} 
To measure affective polarisation, I divide respondents into partisan groups, using survey questions about whether they feel closer to one party compared to the others, and if yes, then which party that is. The partisan groups also include "leaners", i.e. the respondents who initially answered that they are not close to any party, but then answered affirmatively to the follow-up question of whether they at least feel "a little closer" to one political party compared to others. Several countries and elections had to be dropped from the sample, because their questionnaires did not include the partisan identity follow-up question, resulting in much smaller partisan groups.

To capture the partisan affect, I use the following question in the CSES survey:

"I'd like to know what you think about each of our political parties. After I read the name of a political party, please rate it on a scale from 0 to 10 , where 0 means you strongly dislike that party and 10 means that you strongly like that party."

I compile the average like-dislike scores of each partisan group towards their own and all the competing parties into a data matrix, where each row indicates the like-dislike scores a respective partisan group has assigned to every party and each column, and correspondingly, consists of the evaluations a respective party has received from every partisan group. The diagonal axis of the like-dislike matrix indicates the in-party evaluations, while all other cells consist of out-party evaluations. All country like-dislike matrices are displayed in Appendix A.

Then, I use the previously presented Affective Polarisation Index (API) equation to calculate the degree of AP in each country after each election. ${ }^{7}$ Party vote shares are calculated in decimals (e.g. $40 \%=0.4$ ) and the like-dislike scale goes from 0 to 10; thus, the API scores can theoretically range from -10 to 10 . However, scores that remain below 0 would indicate that partisans' out-party evaluations are higher than in-party evaluations. Such "reversed" AP would not correspond to the theoretical expectations or previous findings. Therefore, I assume that the actual API scores will be above 0 and the higher the score, the greater the degree of AP.

To measure ideological (left-right) polarisation, I use the Party Polarisation Index developed by Dalton (2008), but in a slightly adjusted version that fits the aims of this article better. Dalton's

\footnotetext{
${ }^{7}$ The aggregate vote share of the included parties varies between $84 \%$ and $100 \%$, because in some countries there are many small non-parliamentary parties that altogether gather a considerable vote percentage. To ensure better comparability of the index scores across countries, I normalised party vote shares for both AP and IP calculations (e.g. if a party got $30 \%$ of the votes and the aggregate vote share of the parties included in the survey is $90 \%$, then the relative vote share is $30 / 90 * 100=33.33 \%$ ).
} 
index captures the dispersion of party placements around the mean left-right position of the system, weighted by the vote share of each party. The index measures IP on the supply side, although via public perceptions: party left-right placements are determined by the average score the survey respondents have assigned to parties. I find such an approach suitable for my purposes, as also the dependent variable - AP - is based on voter attitudes/perceptions.

As mentioned previously, I define IP on both the supply and demand sides. Therefore, I also calculate the demand side Dalton's index, based on the average left-right self-placements of party supporters. The final ideological polarisation index (IPI) used in the IP-AP models in the empirical section is the average of the supply and demand side measures:

$\mathrm{IPI}=\left(\mathrm{IPI}_{\text {supply }}+\mathrm{IPI}_{\text {demand }}\right) / 2$.

For a more detailed explanation of measuring IP in this article, see Appendix B.

\section{Results}

\section{Levels of affective polarisation in Europe and the United States}

The levels of AP in European countries and the United States, as measured by the Affective Polarisation Index (API), are presented in Table 1. The first important revelation is that intense AP is highly present in European party systems, and the United States is far from being at the head of the pack. This is a remarkable result, considering that in the USA the level of AP is unequivocally considered to be very high. Within Europe, significant regional differences come to the fore. The average API score exceeds 5 in the Central Eastern European (CEE) and Southern European (SE) regions, while none of the Northwestern European (NWE) countries reaches the score of 5 and the average is barely above 4 . Table 1 demonstrates that even the most affectively polarised NWE countries rank lower than the least polarised ones from CEE and SE, with the exception of Great Britain where the API score narrowly exceeds one CEE country (Estonia). The United States is situated in between the two cohorts, as the average API score is higher than the NWE average due to a notable increase between 2008 and 2012, but remains far below most $\mathrm{CEE}$ and SE countries. 
Table 1. Affective Polarization Index score by country

\begin{tabular}{|c|c|c|c|c|c|}
\hline Country & Time 1 & Time 2 & Time 3 & Average & Change \\
\hline Bulgaria (2014) & - & - & 6.68 & 6.68 & \\
\hline Portugal $(2009,2015)$ & - & 4.72 & 6.14 & 5.43 & 1.42 \\
\hline Czech Rep. $(2006,2010,2013)$ & 5.63 & 5.25 & 5.23 & 5.37 & -0.40 \\
\hline Slovakia $(2010,2016)$ & - & 5.14 & 5.38 & 5.26 & 0.24 \\
\hline Montenegro (2012) & - & 5.25 & - & 5.25 & \\
\hline Spain (2008) & 5.02 & - & - & 5.02 & \\
\hline Greece $(2009,2012)$ & - & 4.54 & 5.45 & 5.00 & 0.91 \\
\hline Serbia (2012) & - & 4.89 & - & 4.89 & \\
\hline Poland $(2005,2007,2011)$ & 4.37 & 4.73 & 5.22 & 4.78 & 0.85 \\
\hline Croatia (2007) & 4.54 & - & - & 4.54 & \\
\hline Latvia (2010) & - & 4.50 & - & 4.50 & \\
\hline Great Britain (2015) & - & - & 4.48 & 4.48 & \\
\hline Estonia (2011) & - & 4.46 & - & 4.46 & \\
\hline France (2007) & 4.45 & - & - & 4.45 & \\
\hline United States $(2008,2012)$ & 3.97 & 4.80 & & 4.38 & 0.83 \\
\hline Sweden $(2006,2014)$ & 4.17 & - & 4.36 & 4.27 & 0.19 \\
\hline Denmark (2007) & 4.24 & - & - & 4.24 & \\
\hline Switzerland (2011) & - & 4.10 & - & 4.10 & \\
\hline Austria (2008) & 4.10 & - & - & 4.10 & \\
\hline Germany $(2005,2009,2013)$ & 4.25 & 3.80 & 4.10 & 4.05 & -0.15 \\
\hline Finland $(2007,2011,2015)$ & 3.67 & 4.02 & 3.88 & 3.86 & 0.21 \\
\hline Iceland $(2007,2009)$ & 3.81 & 3.85 & - & 3.83 & 0.04 \\
\hline Netherlands $(2006,2010)$ & 2.69 & 2.83 & - & 2.76 & 0.14 \\
\hline Southern Europe (SE) & & & & 5.15 & \\
\hline Northwestern Europe (NWE) & & & & 4.01 & \\
\hline Central Eastern Europe (CEE) & & & & 5.09 & \\
\hline $\mathrm{N}$ & 12 & 15 & 11 & $4.60^{1}$ & \\
\hline
\end{tabular}

Notes: The exact years of the election after which API calculations were made are listed in the brackets after the country`s name, in respective order. Average of the whole sample and the regional averages are weighted by country to take into account that the number of API scores varies from one to three among countries. Sources: Comparative Study of Electoral Systems database, Module III and Module IV; author's calculations.

The finding that CEE and SE countries exhibit very high levels of AP might not seem particularly striking at first sight. These regions are known for their general distrust towards political parties (Rose 2009; Ignazi 2017) and negative like-dislike evaluations are to be expected. However, the results presented here show something different than a uniform pattern of dislike and rejection. The country like-dislike matrices (see Appendix A) in CEE and SE countries demonstrate that partisans are actually highly positive towards their own party. This is slightly surprising, considering the high electoral volatility in these regions (Ibid.), as it could 
take time before partisans develop a strong positive affect towards new parties. Moreover, the attitudes towards out-parties are clearly differentiated: some receive extremely low evaluations, while others are perceived with moderate dislike or even positively. This suggests that there is a more elaborate affective structure evident in CEE and SE countries than just general dislike towards political parties.

Table 1 also reveals substantial variation within the regions and some notable temporal movements in single countries. In CEE, there are countries with rather average levels of AP, such as Estonia, Latvia and Croatia, but also party systems that are affectively extremely polarised, the most outstanding example being Bulgaria with the API score of 6.68. Among the NWE group, variance is substantially smaller, as most countries remain in the interval between 3.8 and 4.5. The sole exception here is the Netherlands, which is by far the least affectively polarised party system in this sample with API values under 3 in both 2006 and 2010 elections. In all three SE countries included in this study, the average API scores remain between 5 and 5.4. However, Table 1 displays some interesting temporal variations in Greece and Portugal: the rather average API scores in 2009 (4.54 and 4.72, respectively), increased to 5.45 in Greece by 2012 and to 6.14 in Portugal by $2015 .{ }^{8}$ A comparably steep surge in AP is recorded in Poland between 2005 and 2011. These dynamics will be discussed more thoroughly in the next subsection.

API indicates the average weighted difference between the two central components: in- and out-party evaluations. In the extant literature on AP, more attention has been dedicated to outparty evaluations as the more intriguing part of the equation. The cross-national variation in the level of AP in Europe is also - similarly to the temporal increase in the USA - mostly driven by out-party hostility, as the out-party evaluations vary much more significantly than in-party feelings. Table 2 demonstrates that the average weighted out-party rating in NWE countries is almost 4 out of 10 , which could be considered as only a moderate dislike. In CEE, the same indicator is barely over 3 and in SE only 2.74, signifying a much more intense out-party rejection. In the USA, the average out-party evaluation over two elections is higher than in CEE and SE (3.33). Meanwhile, the average in-party evaluation is around 8 out of 10 in all three European regions, while being slightly lower in the USA (7.72). At the country level, there is almost twice as much variation in the weighted average out-party evaluations compared to the in-party attitudes. The former ranges from 2.05 (Bulgaria 2014) to 5.20 (Netherlands 2006),

\footnotetext{
${ }^{8}$ Unfortunately, newer data on Spain is not available, but it would not be surprising to see similar developments there.
} 
with the standard deviation of 0.73, while the latter extends from 7.31 (Spain 2008) to 8.94 (Portugal 2015), with the standard deviation of 0.41 (see Appendix C for these indicators per country and election). Interestingly, it seems that the high level of general distrust towards political parties in CEE and SE countries has no bearing on the in-party evaluation. Across the country sample, there is no correlation between the average in-party and out-party evaluations, suggesting that the two parts of the API equation could be influenced by separate factors.

Table 2. Average in- and out party evaluations, and average partisan and voter turnout percentages by region

\begin{tabular}{lccccc}
\hline Region & N of countries & $\begin{array}{c}\text { Average in- } \\
\text { party } \\
\text { evaluation }\end{array}$ & $\begin{array}{c}\text { Average out- } \\
\text { party } \\
\text { evaluation }\end{array}$ & $\begin{array}{c}\% \text { of } \\
\text { partisans }\end{array}$ & $\begin{array}{c}\text { Voter turnout } \\
\%\end{array}$ \\
\hline $\begin{array}{l}\text { Northwestern } \\
\text { Europe }\end{array}$ & 10 & 8.00 & 3.98 & 74.3 & 72.8 \\
$\begin{array}{c}\text { Central Eastern } \\
\text { Europe }\end{array}$ & 9 & 8.21 & 3.13 & 57.6 & 59.4 \\
$\begin{array}{l}\text { Southern } \\
\text { Europe }\end{array}$ & 3 & 7.89 & 2.74 & 62.9 & 66.1 \\
$\quad 1$ & 7.72 & 3.33 & 81.7 & 56.6 \\
United States & 1 & & & \\
\hline
\end{tabular}

Note: Average in- and out-party evaluations are on a scale from 0 to $10 .{ }^{1}$ Average weighted (i.e. accounting for party size) in-party evaluation of the region, also weighted by country to take into account that the number of scores included from one country varies from one to three (see Table 1); ${ }^{2}$ Average weighted out-party evaluation of the region, also weighted by country; ${ }^{3}$ Including "leaners". Sources: Comparative Study of Electoral Systems, Module III and Module IV; author's calculations.

A glimpse at the partisan like-dislike matrices reveals that the "fear and loathing" between the Democrats and the Republicans is nothing outstanding compared to the partisan animosity evident in several European countries. In 2012, the average Republican rating to the Democratic Party was 2.91 out of 10, and Democrats "retaliated" with 3.09. In five European countries in this sample (Bulgaria, Greece, Spain, Montenegro and Poland), the average weighted out-party evaluation is significantly lower. However, the average accounts for all out-party evaluations, also including some more positive ratings. Attitudes between specific parties are often much more extreme. For example, after the 2012 Greek elections, the right-conservative ND party supporters rated the main competitor - left-radical Syriza - with 1.38, while Syriza partisans assigned 1.61 to ND. Such numbers are shattering, considering that these were and are the two 
biggest political parties in Greece that together gathered almost 60 per cent of the vote. Yet, this seems rather "moderate" in comparison to Bulgaria, where the supporters of the dominant right-wing party (GERB) evaluate the second and the third biggest party with 1.06 and 0.53 (!), respectively. The capacity of this article does not allow the description of many other examples of similar inter-party hostility, but the essence of the results is clear: "fear and loathing across party lines" is definitely evident in European party systems.

Before proceeding with the analysis, I want to address the previously mentioned caveat of API not accounting for the non-partisans in the electorate. As we see from Table 2, in NWE countries, $74.3 \%$ of the respondents claimed to feel at least somewhat closer to one political party than the others, while in SE the percentage is 62.9 and in CEE 57.6. In the USA, the average partisan percentage is 81.7 , but it is not the highest partisan percentage in the whole sample (see Appendix C). Although the differences are significant, I find them not to be as vast as to disallow meaningful comparisons regarding AP. Moreover, in Europe, the partisan percentage aligns closely with the average voter turnout of the region. It looks as if in CEE and SE countries, the percentage of people who are involved in electoral politics by supporting a party or at least taking part in elections, is just lower. The people who have chosen a party, however, possess intense partisan feelings. I find it likely that this has - similarly to what has been found in the USA - significant consequences for the functioning of the party system and society at large. Therefore, I believe that the cross-national/regional and temporal variations presented in this section merit further attention and explanations. The next section will provide first steps in this endeavour.

\section{Affective polarisation and ideological polarisation: related, but not the same}

In this section, I analyse the IP-AP relationship on party system level. IPI scores confirm the continuing importance of the left-right dimension in European party systems, as parties are clearly divided on left-right basis in most of the countries (see Appendix C). Also, party supporters are ideologically well-aligned with their party, indicated by their average left-right self-placements. ${ }^{9}$ To untangle the relationship between IP and AP, I first plot all the IP and AP index scores against each other to get an overview of the distribution of countries into the previously outlined four IP-AP categories and to detect some time trends (Figure 2).

\footnotetext{
${ }^{9}$ The demand and supply side IPs are strongly, but not perfectly correlated to each other $\left(r^{2}=.84\right)$.
} 
Subsequently, to account for the fact that the number of elections per country is uneven in the sample, I plot the country average IPI-API scores to give a more accurate estimation of the linear relationship between the two (Figure 3).

Figure 2 displays a weak statistically not significant relationship between the two manifestations of polarisation $\left(\mathrm{r}^{2}=0.1\right)$. Regarding the possible IP-AP combinations, we see that all the quadrants on Figure 2 are populated. The three SE countries are conveniently in the high IP/high AP group, although in 2009 Greece and Portugal were placed close to the mean value on both axes. From CEE, Czech Republic and Bulgaria also clearly belong to the same group. In the other end of the diagonal we see, somewhat surprisingly, the USA after the 2008 election. From the European cases, Germany is the best example of low IP/low AP, and Finland has by 2015 also moved into this group. Looking at the quadrants where IP and AP are not in accordance, Montenegro and Serbia constitute the perfect cases of ideologically centrist (or just unstructured) party systems that are affectively highly polarised. By 2012, the USA has also moved into the low IP/high AP group, as could have been expected based on the existing literature. It should be considered, though, that in the USA, IP is better captured by the notions "liberal" and "conservative", but even on this scale, it would be lower compared to most European countries. ${ }^{10}$ By 2011, Poland can also be found in this quadrant. From the high IP/low AP sector, we do not find ideal-type cases, although several countries are slightly above sample average in IP and marginally below the AP mean point. Switzerland (2011) and Sweden (2006) constitute the most definite cases of high IP/low AP, but Sweden has moved towards the centre on both axes by 2014. Finally, the party system closest to the "normative ideal" of moderate IP/low AP that was envisaged in the Introduction, is definitely the Netherlands. The cases of Switzerland and the Netherlands concur with the previously outlined prediction that in consociational democracies, ideological distances are not necessarily accompanied by negative partisan feelings.

The three arrows on Figure 2 pinpoint the temporal dynamics in three previously mentioned noteworthy cases: Greece, Portugal and Poland. We can see temporal co-variation in two different directions (IP $\uparrow-\mathrm{AP} \uparrow$ and IP $\downarrow-\mathrm{AP} \uparrow$ ). The two arrows with a direction from left to right indicate a sharp increase in IP that coincides with a comparably large rise in the level of AP in Greece and Portugal. Also, the partisan like-dislike matrices of Greece and Portugal (see Appendix A) reveal an increased animosity that runs mostly along ideological lines, as the left-

\footnotetext{
${ }^{10}$ Relying on the statistics from ANES, presented by Webster and Abramowitz 2017.
} 


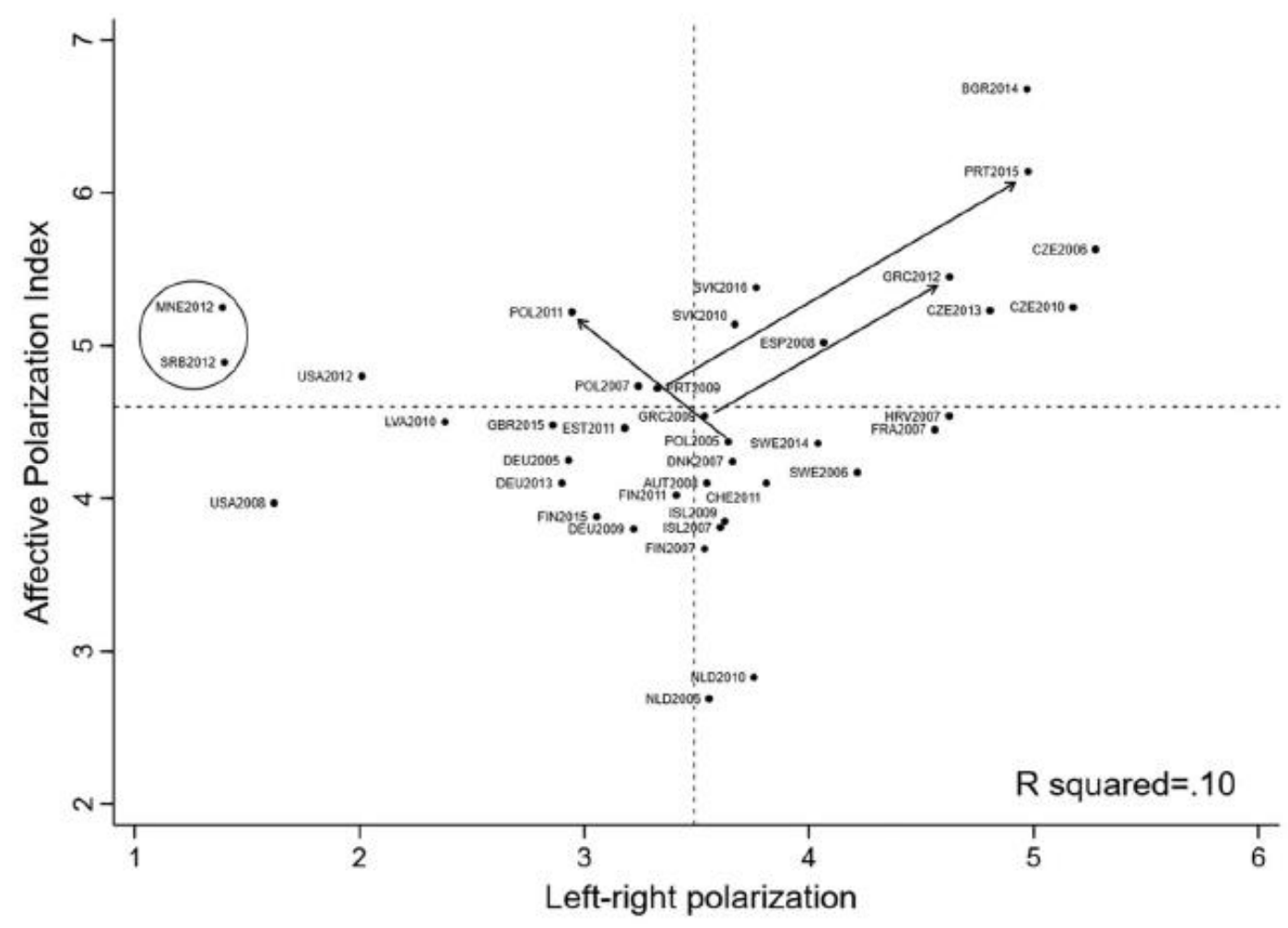

Figure 2. Affective polarisation as a function of ideological polarisation (combined supply/demand side left-right polarisation index). Notes: The cross-cutting dotted lines indicate the sample arithmetic mean of left-right polarisation ( $x$-axis) and affective polarisation ( $y$-axis), weighted by country to take into account the fact that the number of included elections varies from 1 to 3 among countries.

wing anti-austerity and right-wing pro-austerity parties show very negative attitudes towards each other. These developments are likely to be the consequences of the economic, financial and political crises that have ravaged these countries. It seems that the crisis has emphasised and increased the ideological differences between the parties which, in turn, has intensified partisan feelings. In Greece, the hike in polarisation levels can also be attributed to the significant changes in party vote shares: supporters of the left-radical Syriza had strong negative feelings about the main right-wing party (ND) already in 2009, and vice versa, but by 2012, the vote share of Syriza had risen from 5 to 27 per cent, which means that the weight of the party in polarisation index calculations has increased more than fivefold. Regarding Poland, conversely, we see that a substantial increase in the level of AP coincides with a notable decrease in IP. That is probably the case, as the central conflict in the Polish party system is not so much (anymore) on the left-right axis, but rather between pro-Western modernism, represented by the Civic Platform (PO), and traditional Catholic and national values, represented by Law and Justice (PiS) party (Szczerbiak 2011). Partisan like-dislike matrices 
confirm that the upsurge of AP in Poland, indeed, derives from the sharply increased animosity between these two parties that dominate the Polish political system since 2005 .

Before proceeding with the analysis, it should be addressed that there are two obvious outliers in terms of IP: Montenegro and Serbia. As already discussed, both exhibit very low levels of IP, being the only European countries with Dalton index values under 2. The average perceived left-right placement of almost all Serbian and Montenegrin parties remains between 4 and 6 (on a scale from 0 to 10), and high standard deviations of the perceived placements suggest that respondents do not have a clear idea of how the parties are placed on the left-right dimension. The same applies to partisan self-placements. Montenegro and Serbia have the shortest independent democratic experience among the countries in this sample and it seems that the party systems have not aligned on the left-right axis, or at least voters have very little knowledge of it. Also, the case of USA is problematic due to the previously mentioned issue of "left" and "right" not being so widely used notions there. To avoid distorting the results, I will drop these three cases (Montenegro, Serbia and the USA) from further analysis.

Figure 3 presents the IP-AP plot without these outliers and with country average scores, so each country is represented as one case. Addressing these issues changes the results dramatically: the $r^{2}$ leaps from 0.10 to $0.25{ }^{11}$ The effect size is now statistically significant and also considerable in substantive terms: a 1-point increase in IPI corresponds with 0.57-point rise in API. However, I remain cautious regarding the exact strength of the IP-AP relationship on the party system level, as the effect size is highly contingent on two extreme cases. In addition to the three countries that were already removed, also the Netherlands (very low level of AP) and Bulgaria (very high level of AP) exert a strong influence on the results. Removing the Netherlands would increase the $\mathrm{r}^{2}$ above 0.3, whereas removing Bulgaria would decrease it below 0.15 (removing both leaves the $\mathrm{r}^{2}$ around 0.2). Nevertheless, the relationship is always positive and the distribution of countries below and above the regression line remains the same: the IP model consistently under-predicts AP in CEE and (slightly less) SE countries, while over-predicting it in NWE. The only exceptions to this rule are Croatia and Great Britain, as they deviate from their group by being placed below and above the regression line, respectively.

\footnotetext{
${ }^{11}$ The change is almost completely accountable to the deletion of the three outliers, the effect of using country averages is negligible.
} 


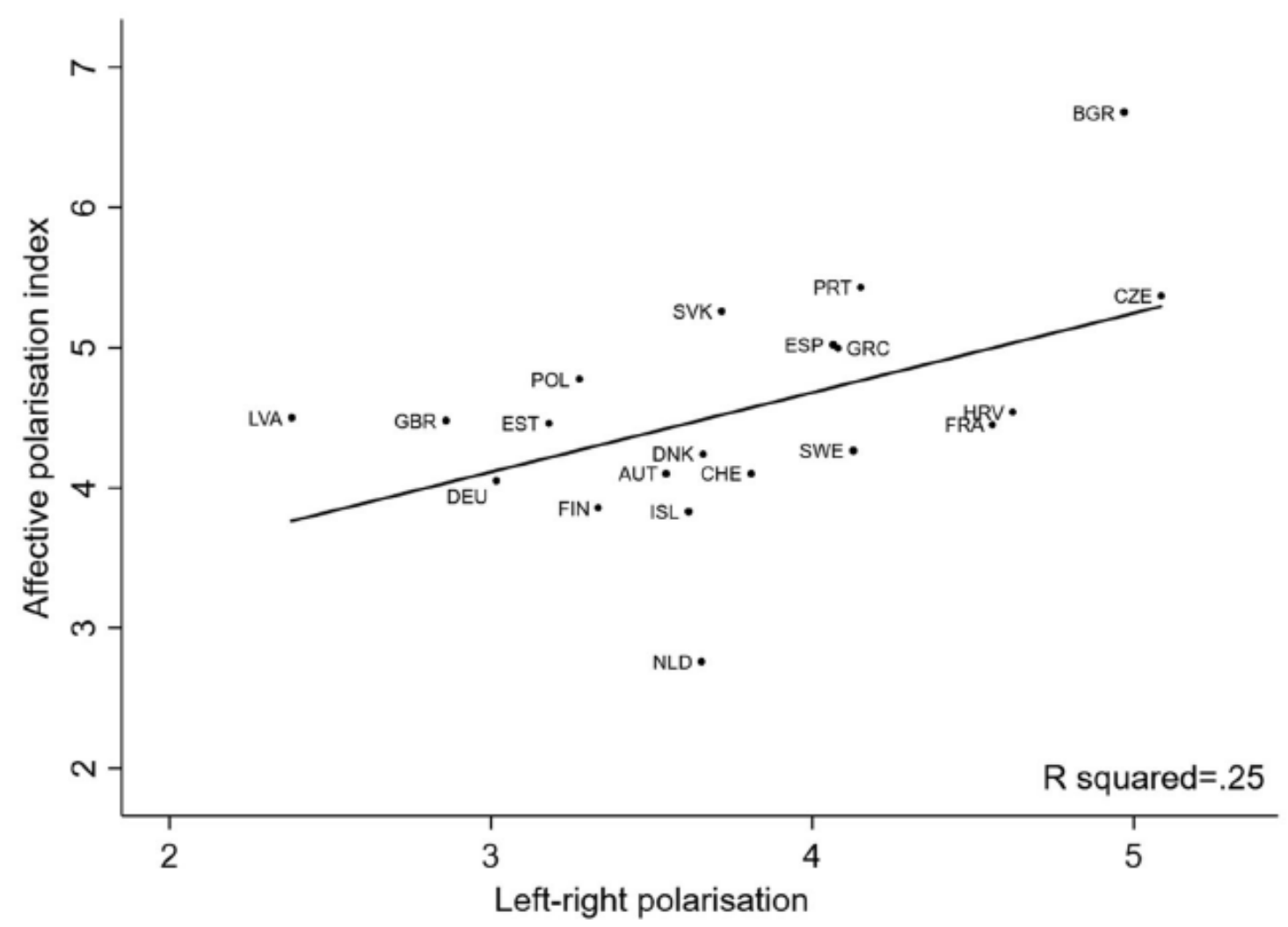

Figure 3. Affective polarisation as a function of ideological polarisation, without Montenegro, Serbia and the United States, and with country average API and IPI scores.

The IP-AP connection becomes more evident in party level data, especially in Northwestern and Southern European, and somewhat less in CEE countries. The average partisan attitudes are often clearly in line with left-right distances. For example, consider Germany (2013), where the supporters of the right-conservative CDU/CSU assign an average score of 5.26 (out of 10) to their main rival, the centre-left SPD. The Green party that is further to the left, gets a rating of 3.80, and the party closest to the left extreme (Linke) is evaluated with 2.18. Similar leftright proximity logic applies to many other countries and parties (see Appendix A). This seems to confirm an intuitively logical assumption that an ideological dimension/issue must be salient in the party system to have an effect on partisan feelings.

On the party system level we have by now established that if only the countries where the leftright dimension has at least some importance are included, there is a consistent positive relationship between IP and AP. However, regardless of the exact country sample, the IP model leaves most of the variation in AP unexplained. At this point, the limitations of the left-right dimension in the context of current European party competition should be discussed. Several 
studies have revealed the emergence of a "transnational" cleavage (Hooghe and Marks 2018) that in some countries cross-cuts the left-right dimension and divides parties into a mainstream block, including traditional socialist, conservative and liberal parties, and a challenger block, consisting of radical, populist and anti-establishment parties (De Angelis 2017). It seems reasonable to hypothesise that polarisation on that dimension explains a substantial part of the remaining variation in API scores. Yet, the placement of countries on Figure 3 does not support this assumption: the NWE countries where we have seen an increased conflict on transnational issues such as European integration and immigration, and the rise of populist Eurosceptic parties, are below the regression line, meaning that AP in these countries is lower than the leftright polarisation predicts. Conversely, the CEE countries that are consistently placed above the prediction line have been found to be less polarised on such issues (Hobolt and Spoon 2012). If polarisation on the alternative dimension would tap into the part of AP that is left unexplained by left-right polarisation, the situation should be the opposite. Thus, it appears that at least on the party system level, adding other ideological dimension(s) into the model would not increase the IP-AP correlation in this set of countries. ${ }^{12}$

This is not to claim that polarisation on the issues pertaining to a transnational cleavage is unrelated to the partisan affect. Again, party level data can be utilised to reveal this connection. Partisan like-dislike matrices demonstrate that right-populist parties clearly stand out in otherwise affectively rather moderate NWE countries. Be it PVV in the Netherlands, SD in Sweden, SVP in Switzerland, and so forth: all of these parties are most intensely disliked by the supporters of many other parties. It is very likely that this is due to the rigid stances the right-populist parties exhibit on issues like immigration, European integration and Islam, and these positions are not fully captured by my one-dimensional approach, as the average left-right placements assigned to these parties are usually not extremely rightist. ${ }^{13}$ Interestingly, AP on the "populist-mainstream" party conflict dimension is highly asymmetric, as the supporters of other parties are much more hostile towards the populist parties, than vice versa. For example, in the Netherlands (2010), the right-populist PVV is perceived very negatively by other partisans: right-liberal VVD supporters evaluate PVV with 3.29 (out of 10), centre-left PvdA partisans with 2.03, social-liberal D66 with 1.64 and Green Left party supporters with 1.3. PVV supporters, on the other hand, give 5.51 to VVD, 4.2 to PvdA, 5.02 to D66 and 4.41 to Green

\footnotetext{
${ }^{12}$ Regarding the cases of Poland and Great Britain, I believe that polarisation on transnational dimension issues such as European integration could hint why they reside above the IP-AP regression line on Figure 3.

${ }^{13}$ E.g. the average placement of SD in Sweden (2014) is 7.2, PVV in the Netherlands (2010) 7.8.
} 
Left. Moreover, the in-party evaluations of PVV partisans are very low (6.83) compared to the supporters of other parties. Such affective asymmetry is taming the level of AP in NWE countries.

In sum, this cross-national analysis reaches a similar conclusion as the individual level studies conducted in the USA: IP and AP are related to each other, but a substantial part of the variation in AP remains unexplained by IP, regardless of how ideology is operationalised.

\section{Discussion}

The results presented in this article reveal that affective polarisation is very acutely present in European multiparty systems. The "fear and loathing" Iyengar and Westwood (2015) observe between the Democrats and the Republicans is not merely evident in Europe, but in many cases even more intense compared to the USA. If partisans evaluate another party with 0 or 1 on a scale from 0 to 10 , that clearly indicates strong animosity, or even hatred. As the country likedislike matrices reveal, there are many partisan groups whose average evaluation towards some other parties remains under 2 and even under 1 . Thus, we are not talking about a few especially militant partisans, but about whole groups who are, on average, extremely hostile towards other parties. The consequences such systematic loathing could have to the functioning of European party systems and societies constitutes a promising avenue for future research.

As for the foundations of AP, the results suggest that ideological differences offer only a partial explanation, as the majority of cross-national variation remains unexplained. Although IP and $\mathrm{AP}$ are in positive correlation as expected, we can see that a relatively high level of ideological polarisation does not necessarily lead to strong interparty hostility, whereas ideologically not centrifugal party systems can still be affectively very polarised. These findings confirm that ideological and affective polarisation should be considered as distinct concepts, and when evaluating the degree of polarisation in some party system, it should be specified which type of polarisation we are talking about.

The main puzzle arising from these findings is: what explains the part of the variation in AP that is left unaccounted for by IP? The distribution of countries on the IP-AP plots presented in the previous section could help make some predictions on that matter. In the countries where there is a highly salient ethnic division and political parties representing ethnic minorities have a considerable representation in the parliament (Bulgaria, Slovakia, Estonia, Latvia, 
Montenegro), AP is consistently higher than IP would predict. This suggests that, as some of the US scholars (like Iyengar et al. 2012), we could search explanations to AP from social identity foundations. From such a perspective, high AP in some ethnically divided CEE countries could partly derive from tribalistic roots. Of course, some other social identities could have a similar effect on partisan feelings, for example religion being one potentially important line of division (for a discussion of ethnic/religious divisions and AP, see Westwood et al. 2018).

Nevertheless, rational accounts of AP should also not be dismissed in countries where AP is higher than IP would predict. The countries above the IP-AP regression line are, on average, much less wealthy and more corrupt compared to the ones below the line. Consequently, voters in CEE and SE countries could shape their affective evaluations towards the parties more on the basis of valence considerations (Stokes 1963): negative affect could derive from perceived incompetence and corruption. However, it would be then reasonable to assume that partisans are also more skeptical towards their own party; yet, high in-party ratings suggest that this is not the case. This hints that partisans attribute more blame for undesirable political outcomes to out-parties, implying that rational judgments could be influenced by in-group bias. Uncovering the exact cognitive mechanisms behind strong partisan feelings requires elaborate individual level studies.

Whether partisan affect is shaped by ideological differences, ethnic (or some other social) identities or valence considerations, it seems that party elites have an important role in mediating these effects. As Lijphart (1969: 211-212) has pointed out, elites could enhance the potential tensions in society in the hope of gaining political profit, but they could also act with an aim to counteract conflict and find consensus. Thus, it is not surprising that countries known for a consensual policy-making culture such as the Netherlands and Switzerland have low AP, despite moderate-to-high IP (and in the Swiss case, also a high level of ethnic fractionalisation). One could propose that proportional electoral institutions contribute to lower AP in these cases; however, there are also proportional fragmented party systems with very high AP, such as Bulgaria and the Czech Republic. This indicates that a proportional electoral system can provide an impetus for lower AP, but it must be accompanied by consensual elite behaviour.

I hope that this article shows the potential of the affect-based approach for revealing new aspects of the phenomenon of political polarisation, and helps to bring the debate on the concept of affective polarisation into the European context. 


\section{Acknowledgements}

I thank Alexander Trechsel, Hanspeter Kriesi, Oscar Smallenbroek, the participants of the European University Institute's Political Behaviour Colloquium and the 27th ECPR Summer School on Political Parties, and two anonymous EJPR reviewers for their comments and advice that has helped me to significantly improve the quality of this article.

\section{References}

Barber, M., \& McCarty, N. (2015). Causes and consequences of polarization. In Persily, N. (Ed). Solutions to political polarization in America. New York: Cambridge University Press, pp. $15-58$.

Budge, I., \& Laver, M. J. (1992). The relationship between party and coalition policy in Europe: an empirical synthesis. In Laver, M.J. \& Budge, I. (eds). Party policy and government coalitions. London: Palgrave Macmillan, 409-430.

Campbell, A., Converse, P. E., Miller, W. E., \& Stokes, D.E. (1960). The American Voter. New York: John Wiley and Sons.

Dalton, R. J. (2008). The quantity and the quality of party systems party system polarization, its measurement, and its consequences. Comparative Political Studies 41(7): 899-920.

De Angelis, A. (2017). Bridging over troubled water: Electoral availability in European party systems at the time of the Great Recession (2009-2014). An application of Bayesian Ideal Point Estimation. Doctoral Thesis. European University Institute.

Downs, A. (1957). An Economic Theory of Democracy. New York: Harper \& Row.

Esteban, J. M., \& Ray, D. (1994). On the measurement of polarization. Econometrica: Journal of the Econometric Society 62(4): 819-851.

Hansen, K. M., \& Kosiara-Pedersen, K. (2017). How campaigns polarize the electorate: Political polarization as an effect of the minimal effect theory within a multi-party system. Party Politics 23(3): 181-192.

Hetherington, M. J., \& Weiler, J. D. (2009). Authoritarianism and polarization in American politics. New York: Cambridge University Press. 
Hetherington, M. J., \& Rudolph, T. J. (2015). Why Washington won't work: Polarization, political trust, and the governing crisis. Chicago: University of Chicago Press.

Hobolt, S.B. \& Spoon, J.J. (2012). Motivating the European voter: Parties, issues and campaigns in European Parliament elections. European Journal of Political Research 51(6): 701-727.

Hooghe, L. \& Marks, G. (2018). Cleavage theory meets Europe's crises: Lipset, Rokkan, and the transnational cleavage. Journal of European Public Policy 25(1): 109-135.

Ignazi, P. (2017). Party and Democracy: The Uneven Road to Party Legitimacy. Oxford: Oxford University Press.

Inglehart, R. (1990). Culture shift in advanced industrial society. Princetion NJ: Princeton University Press.

Iyengar, S. (2011). The polarisation of the American public: Fear and loathing across party lines. Available online at: https://vimeo.com/30715519

Iyengar, S., Sood, G., \& Lelkes, Y. (2012). Affect, not ideology a social identity perspective on polarization. Public Opinion Quarterly 76(3): 405-431.

Iyengar, S., \& Krupenkin, M. (2018). The Strengthening of Partisan Affect. Political Psychology 39(S1): 201-218.

Iyengar, S., \& Westwood, S. J. (2015). Fear and loathing across party lines: New evidence on group polarization. American Journal of Political Science 59(3): 690-707.

Kriesi, H., Grande, E., Lachat, R., Dolezal, M., Bornschier, S. \& Frey, T. (2006). Globalization and the transformation of the national political space: Six European countries compared. European Journal of Political Research 45(6): 921-956.

Laver, M. J. (1992). Coalition and party policy in Ireland. In Laver, M.J. \& Budge, I. (eds). Party policy and government coalitions. London: Palgrave Macmillan, pp. 41-60.

Lelkes, Y. (2016). Mass polarization: Manifestations and measurements. Public Opinion Quarterly 80(S1): 392-410.

Lelkes, Y., Sood, G., \& Iyengar, S. (2017). The hostile audience: The effect of access to broadband internet on partisan affect. American Journal of Political Science 61(1): 5-20. 
Levendusky, M. S. (2018). Americans, Not Partisans: Can Priming American National Identity Reduce Affective Polarization?. The Journal of Politics 80(1): 59-70.

Lijphart, A. (1969). Consociational Democracy. World politics 21(2): 207-225.

Mair, P. (2007). Left-Right Orientations. In Dalton, R. J. \& Klingemann, H-D. (eds). The Oxford Handbook of Political Behaviour. Oxford: Oxford University Press, pp. 206-222.

Mason, L. (2015). "I disrespectfully agree": The differential effects of partisan sorting on social and issue polarization. American Journal of Political Science 59(1): 128-145.

Mason, L. (2016). A Cross-Cutting Calm: How social sorting drives affective polarization. Public Opinion Quarterly, 80 (S1): 351-377.

Mudde, C., \& Rovira Kaltwasser, C. (2018). Studying populism in comparative perspective: Reflections on the contemporary and future research agenda. Comparative Political Studies 51(13): 1667-1693.

Pardos-Prado, S., \& Dinas, E. (2010). Systemic polarisation and spatial voting. European Journal of Political Research 49(6): 759-786.

Persily, N. (Ed.) (2015). Solutions to political polarisation in America. New York: Cambridge University Press.

Petrocik, J.R., (2009). Measuring party support: Leaners are not independents. Electoral Studies 28(4): 562-572.

Richardson, B. M. (1991). European party loyalties revisited. American Political Science Review 85(3): 751-775.

Rogowski, J. C., \& Sutherland, J. L. (2016). How ideology fuels affective polarization. Political Behavior 38(2): 485-508.

Rose, R. (2009). Understanding post-communist transformation: a bottom up approach. London: Routledge.

Stokes, D. E. (1963). Spatial models of party competition. American political science review 57(2): 368-377.

Sunstein, C.R. (2015). Partyism. University of Chicago Legal Forum 2015(2): 1-26. 
Szczerbiak, A. (2011). Election Briefing No 65: Europe and the October 2011 Polish Parliamentary Election. Working Paper. Sussex European Institute, Brighton.

Warwick, P. (1994). Government Survival in Western European Parliamentary Democracies. New York: Cambridge UP.

Webster, S. W., \& Abramowitz, A. I. (2017). The ideological foundations of affective polarization in the US electorate. American Politics Research 45(4): 621-647.

Westwood, S. J., Iyengar, S., Walgrave, S., Leonisio, R., Miller, L., \& Strijbis, O. (2018). The tie that divides: Cross-national evidence of the primacy of partyism. European Journal of Political Research 57(2): 333-354. 